\title{
Documentation of delayed language development in Upper Egypt
}

\author{
Original \\ Mona Elrabie Ahmed', Montaser Mohamed Mohamed ${ }^{2}$, Rasha Abd Elhameed Ali ${ }^{3}$ and \\ Article \\ Mohammed Elrabie Ahmed ${ }^{4}$ \\ ${ }^{1,4}$ Department of Phoniatrics, Otorhinolaryngology, Head and Neck Surgery, ${ }^{2}$ Department \\ of Pediatrics, ${ }^{3}$ Department of Public Health and Community Medicine, Faculty of Medicine, \\ Sohag University, Egypt
}

\begin{abstract}
Purpose: To identify the magnitude of delayed language development (DLD) cases, impairment-subtypes, and main risk factors within children referred to phoniatric and Neuropediatric Unit at Sohag University (PNUSU), Egypt. This will help in planning and implementing primary prevention strategies and in organizing public and health care awareness campaigns.

Methods: It is a hospital-based descriptive study where hospital records of all cases diagnosed as a language delay presented to PNUSU from January $1^{\text {st }}, 2015$ to December, $31^{\text {st }}, 2015$ were analyzed.

Results: Among 800 cases, DLD due to intellectual disability (ID) is the commonest type (34.4\%) followed by below average borderline intellectual (28.5\%). Risk factors study reveals that $66.7 \%$ of studied children are males, $48.9 \%$ of cases show a history of consanguineous marriage between parents and $20 \%$ of studied children had a positive family history of language, speech, or learning problems. Perinatal and neonatal period risk factors appear most frequently as $54.3 \%$, and the predominant factor is Hyperbilirubinemia.

Conclusion: Reported data reflect the magnitude of language disorders problem in Upper Egypt that necessitates special attention from multi-disciplines toward consanguineous marriage and neonatal Hyperbilirubinemia as both are the highest incidence within investigated cases.
\end{abstract}

Key Words: Delayed language development, early identification, risk factors, sub-types

Received: 25 August 2018, Accepted: 25 September 2018

Corresponding Author: Mona Elrabie Ahmed, M.D, Department of Phoniatrics, Otorhinolaryngology, Head and Neck Surgery, Sohag University, Sohag, Egypt, Tel.: +201011805501, E-mail: daimahmoud@yahoo.com.

ISSN: 2090-0740, November 2019 Vol.20, No.3

\section{INTRODUCTION}

Language development is a central feature of cognitive and social development in humans. Failure of normal language development interferes with a child's ability to understand the code, to produce the code, or both $^{[1]}$. Children with expressive language disorders have difficulty in express their ideas using language. Children with receptive language disorders have difficulty understanding messages, while children with expressivereceptive language disorders have difficulty in both understanding and producing messages. These types of disorders are one of the most frequent developmental disabilities in pediatric populations to the extent that up to $5 \%-15 \%$ of the children have delayed language development $(\mathrm{DLD})^{[2,3]}$. In actuality, DLD in children is a wide set of disorders with heterogeneous outcomes. Some of these children may have other developmental, sensory, or physical problems that explain their language difficulties, such as intellectual disabilities, hearing loss, brain damage, autism spectrum disorders (ASD), Attention deficit hyperactivity disorder (ADHD), environmental/ psychosocial deprivation or combination of two or more of these factors. Others have a primary delayed that no specific explanation for language delay is identified; these children are generally diagnosed as specific language impairment (SLI) $)^{[4]}$.

Studies have been exploring possible contributing biological and environmental factors as a way of predicting which children are most likely to have ongoing language problems. Thus, identifying the main risk factors related to the children and their parents associated with language pathology may provide a useful guide for the early identification of children who may someday develop any kind of language disorder. Moreover, developmental screening and early identification is critical in minimizing the adverse long-term consequences and in optimizing speech and language development ${ }^{[5-7]}$. As language development provides a central role in learning and social relationships, children with language delays are at increased risk for different type of learning disabilities ${ }^{[8-10]}$, emotional, social, and behavior problems ${ }^{[11]}$. In adulthood, children who had language delayed may hold lower skilled jobs 
or unemployed compared to control children ${ }^{[12]}$. There are also economic impacts of rehabilitation, special education services, underemployment, and unemployment ${ }^{[4,13]}$.

Unfortunately, reliable data with respect to the magnitude, the categories, the nature of language disorders, as well as the possible risk factors are not available in most of the developing countries. A condition that constrains planning prevention and early rehabilitation services of these children. These services and plans are, in fact, pivotal for improve the language skills and reduce the functional impact of persistent disorders. This issue is very severing in Upper Egypt due to the scarcity of proper awareness and health care programs pertaining to this type of disorders. Thus, the prime objectives of this study

are:

(i) to collect reliable data about the number of children referred to the phoniatric and Neuropediatric Unit at Sohag University (PNUSU), Egypt during the physical year 2015; (ii) to identify the percentage of different language disorders subtypes; (iii) to detect the socio-demographic characteristics and their possible risk factors. Identifying risk factors that may predispose to communication delays or disorders in infants is an important priority to strengthen primary prevention strategies.

\section{MATERIAL AND METHODS}

\section{Research design}

The current research is a hospital-based descriptive study where hospital records of all cases of language delay presented to the PNUSU from January $1^{\text {st }} 2015$ to December $31^{\text {th }} 2015$ were reviewed to determine trends, causes and determinants of their language delay among these patients. Choosing the hospital records of such year was based on completeness of the patients' data in these records.

\section{Participants}

The hospital records of all children who were definitely diagnosed as DLD during 2015 were reviewed and included in the study.

\section{Study instrument}

A structured form of two sections was designed to extract the needed information from the selected hospital records. The first section included socio-demographic data of the children and their parents (i.e., age, gender, residence, maternal age and job, parental consanguinity, number of children in the family, and birth order of the studied child). The second section included detailed prenatal, natal, and postnatal history especially the potential risk factors for language presence of neonatal disorders such as postnatal hyperbilirubinemia (serum bilirubin level, treatment), history of hypoxia, respiratory distress, infections, seizures, admission to a neonatal intensive care unit (NICU) (causes and duration of admission), milestone of development and illnesses of early childhood. Detailed data about the parent-child language interaction were also included. More specifically, the second section also included the following: (i) language assessment using a standardized tests for language scale and quantitative measures of communication difficulties, determined by age $^{[14]}$; (ii) formal testing for psychometric evaluation that was done using the Vineland social maturity ${ }^{[15]}$; (iii) cognitive performance that was routinely evaluated by Stanford Binnet Intelligence Scale $4^{\text {th }}$ Arabic version for determination of intelligence quotient (IQ) (scores are given for verbal, performance, and global $\mathrm{IQ}^{[16]}$; (iv) a battery of selected investigations (e.g., childhood autism rating scale (CARS) and Attention Deficit Hyperactivity disorder Test (ADHDT) ${ }^{[17]}$ and based on Diagnostic and Statistical Manual Disorders, Fourth Edition (DSM-IV) ${ }^{[18]}$; (v) hearing sensitivity evaluated in audiological department at Sohag University, Egypt; (vi) electroencephalography and neuroimaging (CT and MRI) computed tomography; and (vii) thyroid function and other laboratory assessment done when only indicated.

\section{Ethical considerations}

This work complies with the ethical standards of the relevant regional and institutional guidelines on human studies and with the Declaration of Helsinki.

\section{Statistical analysis}

All statistical analyses of the current study were carried out using the SPSS software for Windows (version 16.0, Chicago, IL, USA). Sample characteristics mean and standard deviation (SD) were used in summarizing variables while percentages were used for categorical variables.

\section{RESULTS}

A total of 800 Arabic speaking Egyptian children with DLD presented to the clinic through a year were enrolled in the present study. The children's ages ranged between 18 months to more than 60 months. As shown in (Table 1), $66.7 \%$ of the studied children were males (533 cases) and $75.9 \%$ were residing in urban areas (607 cases). The data presented in (Table 1) indicates that only $13.6 \%$ of the studied cases presented for medical advice in the first two years while $30.8 \%$ of the cases presented at age between 2 and 3 years and $55.6 \%$ presented after 3 years of age.

A closer look to the distribution of different types of DLD in those children (Table 2), revealed that, the commonest type (275 cases; $34.4 \%$ ) was DLD due to Mental Retardation (MR) or intellectual disability/intellectual developmental disorder (ID/IDD). The ID/IDD is a new 
terminology introduced by the American Psychiatric Association diagnostic and statistical manual, $5^{\text {th }}$ Edition $(\text { DSM-5 })^{[1]}$. Other delayed language subtypes of the studied samples were: below average borderline intellectual functioning, hearing impairment, environmental, SLI, brain damaged motor handicapped, autism spectrum disorders were $28.5 \%, 21.5 \%, 7.5 \%, 3.5 \%, 2.4 \%, 1.75 \%$, respectively. The lowest reported cases were for ADHD $(0.5 \%)$. In general, all different language delayed subtypes showed a clear predominance of male over female as shown in (Figure 1) and the corresponding data listed in (Table 2).

Table 1: Socio-demographic data of the studied cases of delayed language

\begin{tabular}{cc}
\hline Characteristic & Summary statistics, Number (\%) \\
\hline Age & $109(13.6)$ \\
$\leq 2$ years & $246(30.8)$ \\
Between 2 and 3 years & $280(35.0)$ \\
Between 3 and 5 years & $165(20.6)$ \\
$\geq 5$ years & \\
Gender & $533(66.7)$ \\
Male & $267(33.3)$ \\
Female & \\
Locality & $607(75.9)$ \\
Urban & $193(24.1)$ \\
Rural &
\end{tabular}

Table 2: Distributions of the studied cases of language delay with respect to subtypes and gender

\begin{tabular}{lcccccc}
\hline Subtypes & \multicolumn{2}{c}{ Male } & \multicolumn{2}{c}{ Female } & \multicolumn{2}{c}{ Total } \\
\hline & No & $\%$ & No & $\%$ & No & $\%$ \\
Intellectual disability & 190 & 69.1 & 85 & 30.9 & 275 & 34.4 \\
Below average mentality & 153 & 67.1 & 75 & 32.9 & 228 & 28.5 \\
Hearing impairment & 112 & 65.1 & 70 & 40.7 & 172 & 21.5 \\
$\begin{array}{l}\text { Environmental } \\
\text { deprivation }\end{array}$ & 42 & 70.0 & 18 & 30.0 & 60 & 7.5 \\
$\begin{array}{l}\text { Specific language } \\
\text { impairment }\end{array}$ & 20 & 71.4 & 8 & 28.6 & 28 & 3.5 \\
$\begin{array}{l}\text { Brain damaged motor } \\
\text { handicapped }\end{array}$ & 11 & 57.9 & 8 & 42.1 & 19 & 2.4 \\
$\begin{array}{l}\text { Autism Spectrum } \\
\text { Disorders }\end{array}$ & 10 & 71.4 & 4 & 28.6 & 14 & 1.8 \\
ADHD & 4 & 100 & 0 & 0.0 & 4 & 0.5 \\
\hline
\end{tabular}

According to the performed IQ tests values, intellectual disability (ID) cases had been further classified into mild, moderate, severe, and profound. (Figure 2) shows that the percentage of the ID of mild-type (160 cases from a total of $275 \mathrm{MR}$ cases) is $58.2 \%$, the moderate is $24.7 \%$ (68 cases), the severe is $11.6 \%$ (32 cases), and the profound is $5.5 \%$ ( 15 cases $)$.

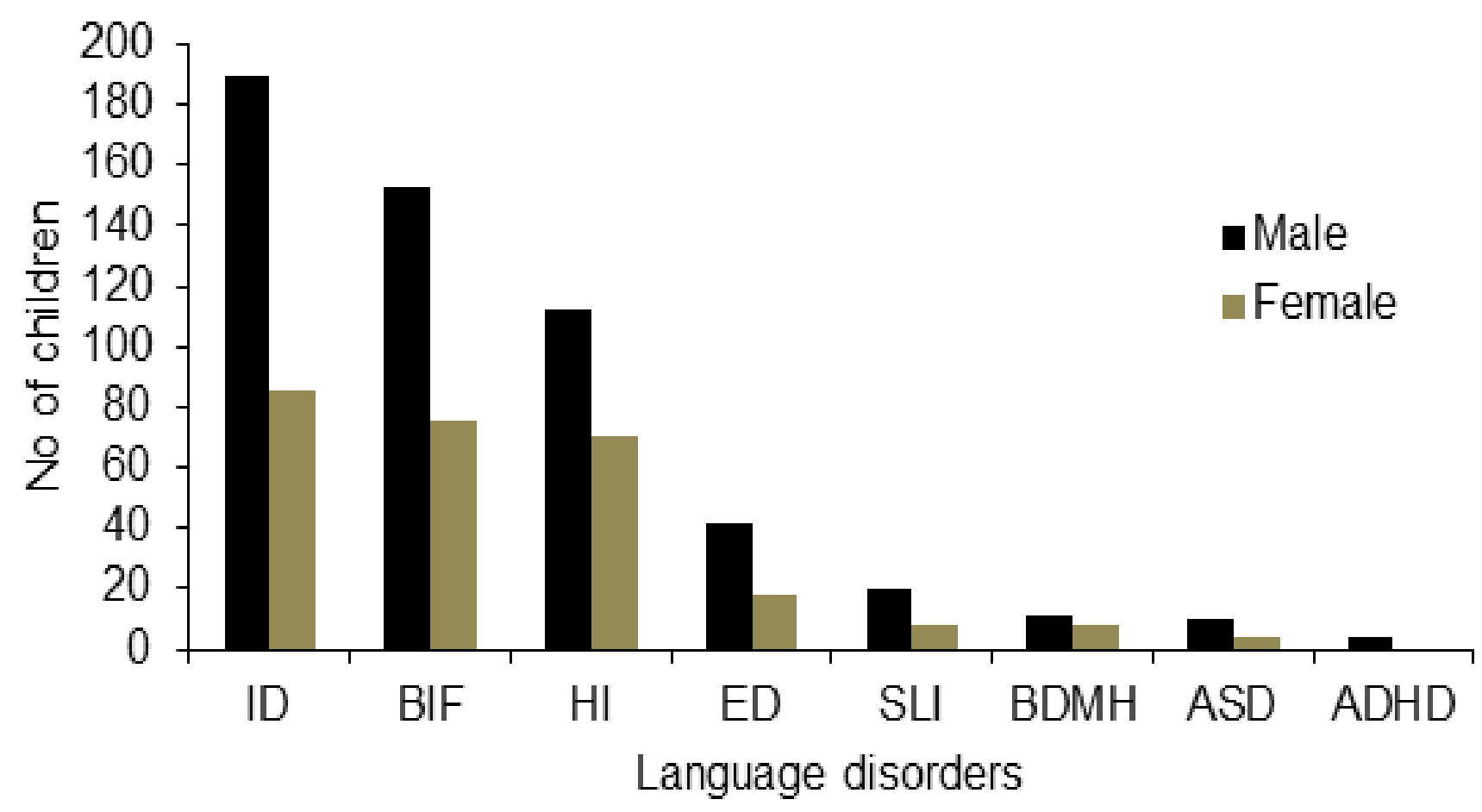

Fig. 1: Distribution of the studied cases of language delay with respect to subtypes and gender; Intellectual disability (ID); Borderline intellectual functioning (BIF); Hearing Impairment (HI); Environmental Deprivation (ED); Specific Language Impairment (SLI); Brain Damaged Motor Handicapped (BDMH). 


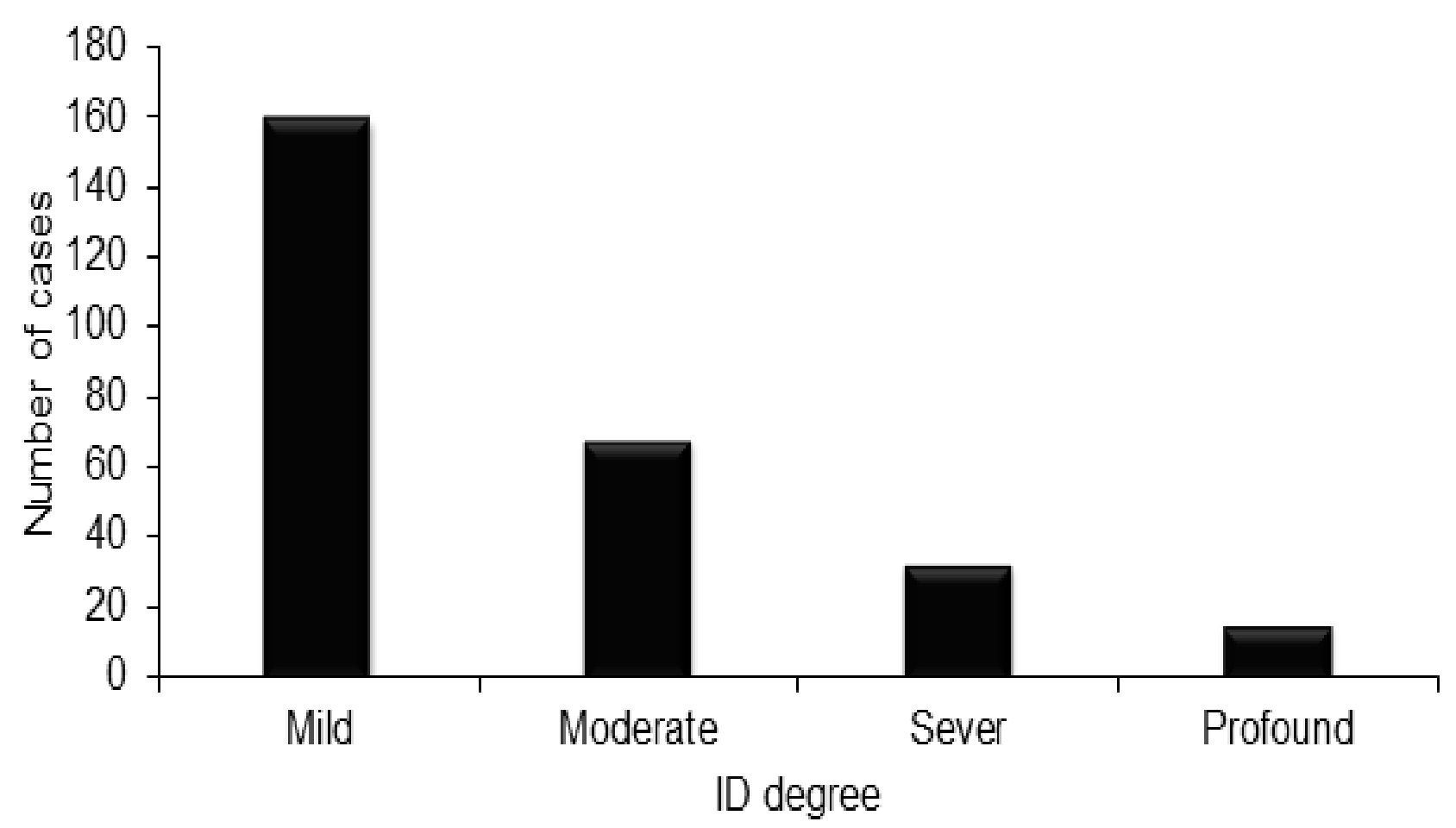

Fig. 2: Intellectual disability (ID) cases classified into mild, moderate, severe and profound according to intelligence quotient (IQ).

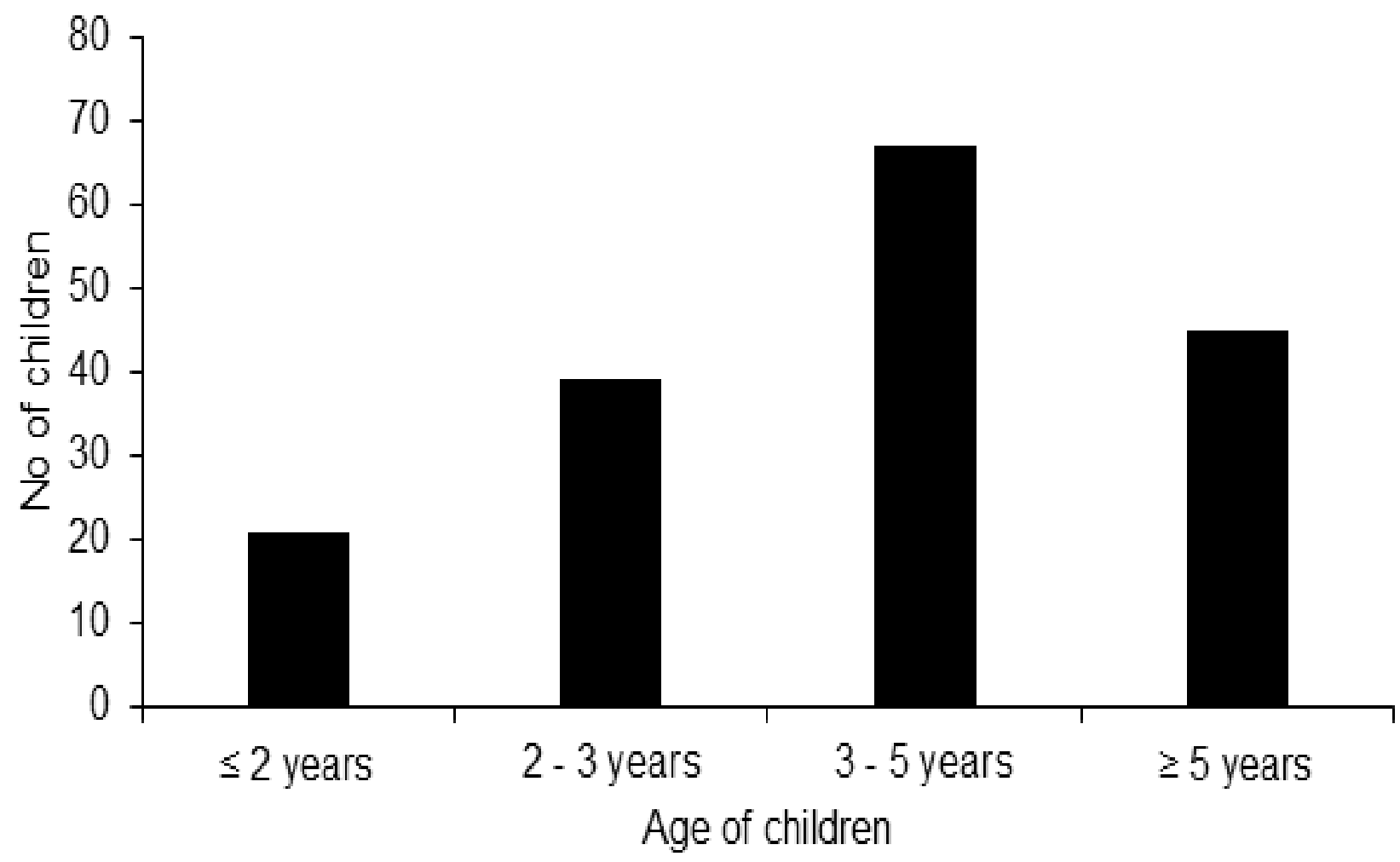

Fig. 3: Distribution of the ages of the studied cases of hearing impairment.

Specific concern had been paid for the presentation age of hearing impaired cases (Figure 3). Among the 172 cases (Table 2) of hearing impairment, 67 cases (39.0\%) were presented between 3-5 years, 45 cases $(26.2 \%)$ after 5 years, 39 cases $(22.7 \%)$ between $2-3$ years, and only 21 cases $(12.2 \%)$ before two years.
Another domain of this study was to identify the possible contributing biological and environmental risk factors related to the children and their parents associated with language delayed. (Table 3) displays distribution of the studied cases of language delay with respect to possible familial risk factors. $48.9 \%$ (391) of cases had a history consanguineous marriage between parents and $20 \%$ of 
studied children had positive family members who were late to talk or had language disorders, speech problems, or learning problems. Referring to the number of children in the family, more than half of the cases (53\%) belonged to families having between 2-3 children, $38 \%$ of them had more than 4 children while $9 \%$ of the families had only one child. It was observed that $90.2 \%$ of the mothers were housewives, and only $9.8 \%$ were working.

Table 3: Distributions of the studied cases of language delay with respect to familial possible risk factors

\begin{tabular}{lcc}
\hline \multicolumn{1}{c}{ Characteristic } & \multicolumn{2}{c}{ Summary statistics } \\
& No. & $\%$ \\
\hline Consanguinity & & \\
Yes & 391 & 48.9 \\
No. & 409 & 51.1 \\
Presence of sisters and brothers & & \\
Alone & 71 & 9.0 \\
With sisters and brothers & 729 & 91.0 \\
Birth order of the child & & \\
First & 260 & 33.0 \\
In between & 232 & 29.5 \\
Last & 298 & 37.3 \\
Twins & 10 & 1.25 \\
No of children in the family & & \\
1 & 71 & 9.0 \\
$2-3$ & 424 & 53.0 \\
$\geq 4$ & 305 & 38.0 \\
Family history & & \\
Yes & 164 & 20.0 \\
No & 636 & 80.0 \\
Maternal age & & \\
$14-24$ years & & \\
$25-35$ years & 354 & 44.4 \\
$\geq 36$ years & 394 & 49.4 \\
Working status of the mother & 52 & 6.2 \\
housewife & & \\
Working mother & 719 & 90.2 \\
\hline & 81 & 9.8 \\
\hline
\end{tabular}

The pre, the peri, and the postnatal period's risk factors were also analyzed and the pertaining data were illustrated in (Table 4). It was interesting to notice that in these periods, the perinatal and neonatal risk factors appeared most frequently in the studied cases as $54.3 \%$ (434 cases) of the total number of cases. Moreover, the predominant risk factor in this period was the Hyperbilirubinemia that had been reported in 264 cases $(61.8 \%)$. Weak or no crying after birth or slow to cry was the second detected risk factors, followed by mixed factors (where more than one risk factor were evident). At a lower percentage, there were vacuum assisted vaginal, placental complications, cord complications and precipitate delivery. Referring to the postnatal period, history of seizures and surgery were the commonest factor among other factors. For the maternal risk factor, pre-eclampsia and oligohydramnios or polyhydramnios were noted to be the most frequent factors.

Table 4: Maternal, Perinatal and neonatal and postnatal risk factors in the study group

\begin{tabular}{|c|c|c|c|}
\hline \multirow{2}{*}{$\begin{array}{l}\text { Factors } \\
\text { Maternal }\end{array}$} & Number & \multicolumn{2}{|c|}{$\%$ from the total } \\
\hline & Pre-eclampsia & 13 & \\
\hline & $\begin{array}{l}\text { Oligohydramnios } \\
\text { or polyhydramnios }\end{array}$ & 9 & \\
\hline & Hypertension & 3 & \\
\hline & Anemia & 2 & \\
\hline & Diabetes Mellitus & 1 & \\
\hline & Bronchial asthma & 1 & \\
\hline & Heart disease & 1 & \\
\hline & Convulsion & 1 & \\
\hline & Fever & 1 & \\
\hline & $\begin{array}{l}\text { Drugs (anti- } \\
\text { depressant) }\end{array}$ & 1 & \\
\hline & & Total $=33$ & $4.13 \%$ \\
\hline \multirow[t]{15}{*}{$\begin{array}{l}\text { Perinatal } \\
\text { and neonatal }\end{array}$} & $\begin{array}{l}\text { Hyperbilirubinemia } \\
\text { ( kernicterus) }\end{array}$ & $264(4)$ & $61.8 \%$ \\
\hline & $\begin{array}{l}\text { Weak or no } \\
\text { crying after birth } \\
\text { or slow to cry }\end{array}$ & 45 & \\
\hline & Mixed risk factors & 33 & \\
\hline & $\begin{array}{l}\text { Abnormal } \\
\text { presentation }\end{array}$ & 18 & \\
\hline & $\begin{array}{l}\text { Prolonged labor } \\
\text { (obstructed labor) }\end{array}$ & 17 & \\
\hline & Birth weight and size & 14 & \\
\hline & $\begin{array}{l}\text { Twins or } \\
\text { multiple birth }\end{array}$ & 10 & \\
\hline & $\begin{array}{l}\text { Respiratory } \\
\text { distress (RDS) }\end{array}$ & 8 & \\
\hline & $\begin{array}{l}\text { Premature rupture of } \\
\text { membranes (PROM) }\end{array}$ & 7 & \\
\hline & Prematurity & 5 & \\
\hline & $\begin{array}{l}\text { Vacuum assisted } \\
\text { vaginal }\end{array}$ & 3 & \\
\hline & $\begin{array}{l}\text { Placental } \\
\text { complications }\end{array}$ & 3 & \\
\hline & Cord complications & 2 & \\
\hline & Precipitate delivery & 1 & \\
\hline & & Total $=434$ & $54.3 \%$ \\
\hline \multirow[t]{6}{*}{ Postnatal } & Seizures & 16 & \\
\hline & Surgery & 9 & \\
\hline & Hypothyroidism & 4 & \\
\hline & Anemia & 4 & \\
\hline & Heart defect & 3 & \\
\hline & & Total $=36$ & $4.5 \%$ \\
\hline
\end{tabular}




\section{DISCUSSION}

Actually, there are no available data about the magnitude, sub-types, as well as the possible risk factors related to delayed language development in most of the developing countries, especially Upper Egypt. Having reliable data considered to be the main stone to constrain planning prevention and early rehabilitation services of these children.

Among the 800 cases of DLD presented through a year, 533 cases $(66.6 \%)$ were boys to be more prone to language disorders and to different language delayed subtypes, in agreement with both national and international literature ${ }^{[6,17,19-24]}$.

In fact, being male is considered as an important risk factor for language disorders. This may be explained by the slow maturation of the nervous system, the effect of testosterone that stops cell death and makes the proper connections difficult ${ }^{[25]}$. Therefore, boys might have a more severe language difficulty than girls and have a higher rate of referral ${ }^{[21-22]}$

In fact, early identification and intervention of a child's language problems are internationally well-acknowledged as they prevent the negative impact and offers better quality of life for the children and their parents which also cost the government less in the long run. In this study, more than half of cases $(55.6 \%)$ were presented for our clinic after 3 years of age while $13.6 \%$ of the cases only were presented in the first two years. Thus majority of the children presented while the critical period for language acquisition and development due to greater neuronal plasticity, has already passed.

Researches confirmed that regardless of the cause of language delay, early identification of speech-language delayed (below 3 years old) is a precondition for early intervention and therefore preventing and/or minimizing the associated problems in communication, literacy and cognition and optimizing speech and language development ${ }^{[5-7]}$.

In the current study, it is noticed that the parents often wait until the child reach 3 years or even more before asking an evaluation for a child who is not talking which is regretfully advised by clinics and/or relatives. Therefore, we urgently need to increase the knowledge of general population and health professionals, such as pediatricians, nurses about normal and impaired language development and confirm the great importance of early identification and early intervention for DLD.

Another worthy finding in this study is that high percentage $(75.9 \%)$ of children were from urban areas while only $(24.1 \%)$ from rural areas. In contrast,
Aboul-Oyoun epidemiological study of communication disorders in Assiut, Upper Egypt, found that the communication disorders were more common in rural areas than urban areas ${ }^{[26]}$. However, we cannot generalize or compare their findings with our results as the current study directed their survey to the children with language problem that referred to our clinic seeking professional advice and treatment. It stills the low percentage of cases from rural areas may indicate a lack of education and or availability of services. Brown et al. Stated that poverty, lack of acknowledge, is a risk factor for both language delay and failure to access appropriate therapies ${ }^{[27]}$. Thus, more attention should direct for the rural areas with respect to the services and planning to raise awareness about DLD.

A closer look to the distribution of different types of DLD reveals that delayed language due to mental retardation or intellectual disability (ID) was the most common clinical diagnosis encountered in the current cases in agreement with the recent study by Abou-Elsaad et al. ${ }^{[24]}$. In fact, it is an important issue for services to estimate the severity of ID cases. According to Salvador-Carulla et al., (2011) ID can be further classified into mild, moderate, severe and profound according to intelligence quotient (IQ) ${ }^{[25]}$. In this study, sever and profound ID was of $17.1 \%$ (47 cases out of a total of 275 children presented in a year with ID). Actually, severe and profound levels have a higher risk of developing health problems and medical complications, and most of them need pharmacological treatments for long term ${ }^{[26-27]}$, as well as a high prevalence of them are severely limited in their ability to understand or comply with requests or instructions, and require intensive constant training and support in various life aspects.

The second common reported subtype was the DLD due to borderline intellectual functioning (BIF) or below average mentality. In fact, delayed language with borderline or below average IQ is barely used as a separate subtype of DLD. In the current study, BIF was viewed as a separate entity as it was noticed that it expresses independent language affection and prognosis. BIF is a controversial and a marginal clinical entity that remains to be clearly defined and for that targeted diagnostics and therapeutic approaches do not exist ${ }^{[28,29]}$. Abou-Elsaad et al. reported that below average DLD subtype was the third commonest cause of DLD among studied children and their study is considered one of the very few papers used the term below average mentality language delayed as a separate entity ${ }^{[24]}$.

The third commonest DLD subtype was that due to hearing impairment. It is interesting to notice that more than two-thirds of the children with hearing impaired were using cochlear implant (125 child $72.7 \%$ ), while only 47 children $(27.3 \%)$ were using hearing aids. The aforementioned high number of hearing-impaired cases compared to previous studies ${ }^{[24-30]}$ focused on Upper Egypt children may be attributed to the recent establishment of a specialized cochlear implant unit at Sohag that offers 
services to most of the Upper Egypt governorates including Sohag, Assuit, Qena, Luxor, Aswan, and Red sea.

Nevertheless, even with continuous improving medical services applied for hearing impaired child, the late presentation of children is still a problem that hampers better prognosis. The current study shows that about $65 \%$ of children presented above 3 years of age. This would direct the attention to the importance of the early identification by hearing screening. It was also noticed in a good percentage of hearing impaired cases that the parents have no idea that if the child diagnosed early and wear hearing aids regularly with language rehabilitation lead to better prognosis and the child can developed near normal hearing child. Some parents have false believes that child with hearing loss mostly will be deaf mute child. In fact, the increase of the awareness of the parents as well as the health professionals about the importance of the early identification and intervention is urgently needed.

Identifying the main risk factors related to language pathology is mandatory for early identification and important priority to strengthen primary prevention strategies. Consanguinity was the most reported associated risk factor after male gender in the present work. Forty-nine percent (392) of cases showed history of consanguineous marriage between parents in agreement with the results of Meliegy and Sabbagh who reported that positive consanguinity was of $43 \%$ of the total considered cases ${ }^{[30]}$. In comparison between different DLD subtypes, $68 \%$ of the total hearing impaired children were from consanguineous parents. The great incidence of consanguineous marriage in our cases highlight the importance of increase the public awareness on congenital and genetic disorders in offspring derived from consanguineous marriage and the importance of genetic counseling.

In similar to previous studies, the current study showed that more than $20 \%$ of studied children have a positive family history ${ }^{[19,31]}$. Moreover, the positive family history incidence is higher among hearing impaired children in comparison to other DLD cases as $38 \%$ from total hearing impaired cases (66 of 172 hearing impaired cases) showed positive family history. The impact of family history may be related to genetic or environmental influences, or to a combination of both.

Interestingly, $90 \%$ of the mothers were housewives. However, this fact does not guarantee the quality of the time spent in situations of mother-child interaction. Most of the women did not report playing with their children, or telling them stories, for instance. Time is spent with physical care: food, and hygiene. The lesser occurrence of being the only child was observed $(9 \%)$. Some studies pointed out that the only child becomes both the target of high parental expectations, usually oriented to the firstborn, and receives typical favors and care ${ }^{[32]}$. In the present study, later born children were more likely to have DLD than children of first born in agreement with previous studies $^{[33-34]}$.

Among the various risk factors examined in the current study, the risk factors of the pre, peri, and postnatal periods were considered. The higher incidence reported here were the perinatal and neonatal risk factors $(52.5 \%)$. Moreover, hyperbilirubinemia was the major reported factor. Bhutani and Johnson-Hamerman reported a significant correlation between neonatal hyperbilirubinemia in the absence of classical kernicterus and speech and language abnormalities in their review. Also they stated that the total serum/plasma bilirubin (TB) level is not the most precise indicator of neurotoxicity ${ }^{[35]}$. Thus, extensive study correlates bilirubin exposures to language development of children are needed as the available data are markedly limited. Moreover, the current study showed that in the pregnancy period, pre-eclampsia was the highest elicited risk factor among maternal causes.

\section{CONCLUSIONS}

A total of 800 Arabic speaking Egyptian children with DLD referred to the Phoniatric and Neuropediatric Unit at Sohag University, Egypt during the physical year 2015 were examined and investigated to determine causes and determinants of their language delay. The most consistently identified risk factors among participated cases were male gender, consanguinity, hyperbilirubinemia, family history of speech and language delay. Such factors should be taken into account during educational programs and services and to help for early identification and intervention of language problems.

Besides, the reported data could explain how much we need a crucial plan for multilevel and integrated programs to raise awareness about the language development disorders in Upper Egypt. It is important to emphasize the great importance of early identification that permits enrollment in an early intervention programs and never wait until children are $\geq 3$ years of age to evaluate their delayed language.

\section{Future directions}

Further study including control group are needed to better understand the strength of association and possible causative factors and their relationship with the different language disorders subtypes.

\section{CONFLICT OF INTEREST}

There are no confilict of interest. 


\section{REFERENCES}

1. American Psychiatric Association. Diagnostic and statistical manual of mental disorders: DSM-5. 5th ed. Washington, DC: American Psychiatric Association, 2013.

2. Zubrick SR., Taylor CL., Rice ML, Slegers DW. Late language emergence at 24 months: an epidemiological study of prevalence, predictors, and covariates, J Speech Lang Hear Res. 50 (2007) 1562-1592.

3. Diepeveen FB., Dusseldorp E., Bol GW., OudesluysMurphy AM., Verkerk PH. Failure to meet language milestones at two years of age is predictive of specific language impairment, Acta Paediatr. 105 (2016) 304310 .

4. Berkman ND., Wallace I., Watson L., Coyne-Beasley T., Cullen K., Wood C., et al. Screening for Speech and Language Delays and Disorders in Children Age 5 Years or Younger: A Systematic Review for the U.S. Preventive Services Task Force [Internet]. Rockville (MD): Agency for Healthcare Research and Quality (US). (2015) Jul. Report No.: 13-05197-EF-1.U.S. Preventive Services Task Force Evidence Syntheses, formerly Systematic Evidence Reviews.

5. Ellis EM. Thal DJ. Early language delay and risk for language impairment, Perspectives on Language Learning and Education. 15 (2008) 93- 100.

6. Harrison LJ., McLeod S. Risk and protective factors associated with speech and language impairment in a nationally representative sample of 4- to 5-year-old children, J Speech Lang Hear Res. 53 (2010) 508-529.

7. Paul D., Roth FP. Guiding Principles and Clinical Applications for Speech-Language Pathology Practice in Early Intervention, Lang Speech Hear Serv Sch. 42 (2011) 320-330.

8. Pennington BF, Bishop DV. Relations among speech, language, and reading disorders, Annu Rev Psychol. 60 (2009) 283-306.

9. Kan PF., Windsor J. Word learning in children with primary Language impairment: ameta-analysis, J Speech Lang Hear Res. 53 (2010) 739-756.

10. Stoeckel RE., Colligan RC., Barbaresi WJ., Weaver AL., Killian JM., Katusic SK. Early speech-language impairment and risk for written language disorder: A population-based study, Journal of Developmental and Behavioral Pediatrics. 34 (2013) 38-44.
11. Yew SGK., O'Kearney R. Emotional and behavioural outcomes later in childhood and adolescence for children with specific language disorders: meta-analyses of controlled prospective studies, J Child Psychol Psychiatry. 54 (2013) 516-524.

12. Felsenfeld S., Broen PA., McGue M. A 28-year followup of adults with a history of moderate phonological disorder: educational and occupational results, J Speech Hear Res. 37 (1994)1341-1353.

13. Conti-Ramsden G., Durkin K. Post School educational and employment experiences of young people with Specific Language Disorder, Lang Speech Hear Serv Sch. 43 (2012) 507-520.

14. Kotby MN, Khairy A, Baraka M, Rifaie N, El Shobary A. Language testing of Arabic speaking children. Proceeding of the XXIII world congress of International Association of Logopedics and Phoniatrics; Cairo; 5 August 1995; p. 6-10.

15. Doll EA. The measurement of social competence: a manual for the Vineland social maturity scale. Educational Test Bureau, Educational Publishers, 1953.

16. Melika L. The Stanford.Binet Intelligence scale. 4th ed. ArabicExaminer's Handbook. Egypt, Cairo: Dar El-Maref Publishing, 1998

17. Gilliam JE. Attention-Deficit Hyperactivity Test. Austin. Texas: PRO-ED; 1995.

18. Diagnostic and statistical manual of mental disorders DSM-IVTR. Washington, DC 2000: American Psychiatric Association; 2000.

19. Silva GM, Couto MI, Molini-Avejonas DR. Risk factors identification in children with speech disorders: pilot study.Codas. 2013; 25 (5):456-62.

20. Reilly S., Wake M., Ukoumunne OC., Bavin E., Prior M., Cini E., et al. Predicting language outcomes at 4 years of age: findings from Early Language in Victoria Study, Pediatrics. 126 (2010) 1530-1537.

21. Henrichs J., Rescorla L., Schenk JJ., Schmidt HG., Jaddoe VW., Hofman A., et al. Examining continuity of early expressive vocabulary development: the Generation R Study, J Speech Lang Hear Res. 54 (2011) 854-869.

22. Hawa VV, Spanoudis G. Toddlers with delayed expressive language: an overview of the characteristics, 
risk factors and language outcomes, Res Dev Disabil. 35 (20140 400-407.

23. Collisson BA., Graham SA., Preston JL., Rose MS., McDonald S., Tough S. Risk and Protective Factors for Late Talking: An Epidemiologic Investigation, J Pediatr. 172 (2016) 168-174.

24. Abou-Elsaad T., Abdel-Hady H. , Baz H. , ElShabrawi D. Language and cognitive outcome for high-risk neonates at the age of 2-3 years - experience from an Arab Country, World J Clin Pediatr. 6 (2017) 24-33.

25. Geschwind N, Galaburda AM. Cerebral lateralization. Biological mechanisms, associations, and pathology: I. A hypothesis and a program for research, Arch Neurol. 42 (1985) 428-59.

26. Aboul-Oyoun A. Epidemiological study of communicative disorders in Upper Egypt. Unpublished doctoral dissertation, Faculty of Medicine. Ain Shams University, Cairo, Egypt; 2000.

27. Brown CM, Beck AF, Steuerwald W., Alexander E., Samaan ZM., Kahn RS., et al. Narrowing Care Gaps for Early Language Delay: A Quality Improvement Study, Clin Pediatr (Phila). 55 (2016) 137-44.

28. Salvador-Carulla L., Reed GM., Vaez-Azizi LM., Cooper SA, Martinez-Leal R., Bertelli M., et al. Intellectual developmental disorders: towards a new name, definition and framework for "mental retardation/intellectual disability" in ICD-11, World Psychiatry. 10 (2011) 175-180.

29. Poppes P, van der Putten AJJ., Vlaskamp C. Frequency and severity of challenging behaviour in people with profound intellectual and multiple disabilities, Res Dev Disabil. 31 (2010) 1269-1275.

30. Meliegy EE., Sabbagh HE. Etiologies of developmental delay in Egyptian children, International Journal of Child Neuropsychiatry. 1 (2004) 29-40.

31. Broomfield J, Dodd B. Children with speech and language disability: caseload characteristics Int J Lang Commun Disord. 2004 Jul-Sep; 39(3):303-24.

32. Eckstein D. Empirical studies indicating significant birth-order-related personality differences, J Individual Psychology. 56 (2000) 481-94.

33. Stanton-Chapman TL, Chapman DA., Bainbridge NL., Scott KG. Identification of early risk factors for language impairment, Res Dev Disabil. 23 (2002) 390-405.

34. Horwitz SM., Irwin JR., Briggs-Gowan MJ, Bosson Heenan JM., Mendoza J., Carter AS. Language delay in a community cohort of young children, J Am Acad Child Adolesc Psychiatry. 42 (2003) 932-40.

35. Bhutani VK, Johnson-Hamerman L. The clinical syndrome of bilirubin-induced neurologic dysfunction, Semin Fetal Neonatal Med. 20 (2015) 6-13. 